\title{
A REVIEW OF SMITH'S FRACTURES
}

\author{
J. E. WoOdyard, EXeter, England
}

In 1847 Smith described an unusual fracture of the lower end of the radius. This injury, though now well recognised, has received little attention in the literature until recent years. Thomas (1957) described nineteen cases (two of them in children) and gave a practical method of classification as well as advising a method of reduction. Ellis (1965) described a plate that could be used to maintain reduction by internal fixation, but did not state the number of cases so treated, nor did he compare the results with those of conservative management.

In the Exeter area about seventy cases of Smith's fracture have been treated in the last few years, and of these, forty-four of the patients have been traced-nine males and thirty-five

TABLE I

Sex Distribution of all Fractures

\begin{tabular}{|c|c|c|c|c|c|}
\hline & Type 1 & Type 2 & Type 3 & Children & Total \\
\hline Male & 2 & 4 & 3 & - & 9 \\
\hline Female & 21 & 9 & 2 & 3 & 35 \\
\hline
\end{tabular}

TABLE II

Age Distribution Related to Type of Fracture

\begin{tabular}{|c|c|c|c|c|c|}
\hline & \multicolumn{5}{|c|}{ Age in years } \\
\hline & 0-20 & $21-40$ & $41-60$ & $61-80$ & Total \\
\hline Type 1 . & - & 1 & 10 & 12 & 23 \\
\hline Type 2 . & 2 & 1 & 5 & 5 & 13 \\
\hline Type 3 & 3 & 一 & 2 & - & 5 \\
\hline $\begin{array}{l}\text { Fracture separation in } \\
\text { children }\end{array}$ & 3 & - & - & - & 3 \\
\hline
\end{tabular}

females (Table I). The age distribution is shown in Table II and closely parallels that of Colles's fracture with its preponderance of middle-aged and elderly women.

Type of fracture-Thomas's classification into three adult radiological types has been found helpful. Fractures of Type 1 are seen usually in older patients (Fig. 1). They are commonly comminuted and accompanied by fracture of the tip of the ulnar styloid. This is the largest group (Tables I and II). The Type 2 fracture is an anterior marginal fracture with anterior subluxation of carpus (Fig. 2). This is the next largest group: in this series, in contrast to that of Thomas, it occurred in older patients more than younger ones (Table II). The Type 3 fracture is slightly oblique when viewed laterally, displaced anteriorly and not comminuted (Fig. 3). It was the smallest of the adult group and was not seen over the age of fifty-three. In no patient was there an associated metacarpal fracture as described by Thomas. The final group, in children aged eleven to fifteen, comprised fracture-separations of the lower radial epiphysis with forward and sometimes radial displacement of the lower fragment (Fig. 4). 
Of the forty-four fractures only one was compound (from direct external injury to the skin) and there were few other injuries to the limbs-certainly none that appeared regularly or in any definite pattern. A curious finding was that only twelve of the forty-four patients had injured their dominant hand.

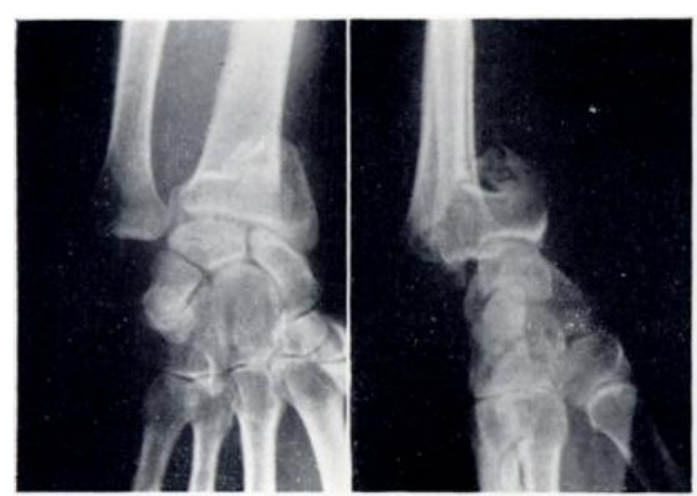

FIG. 1

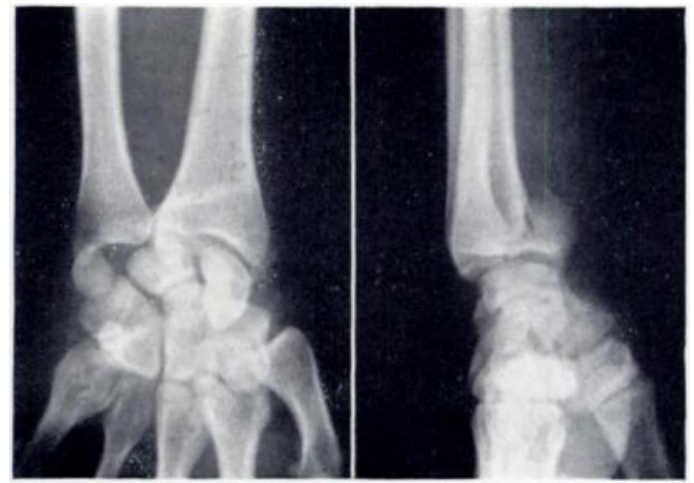

FIG. 2

Figure 1-A severely displaced Type 1 fracture before reduction. Figure 2-A Type 2 fracture showing a little displacement.

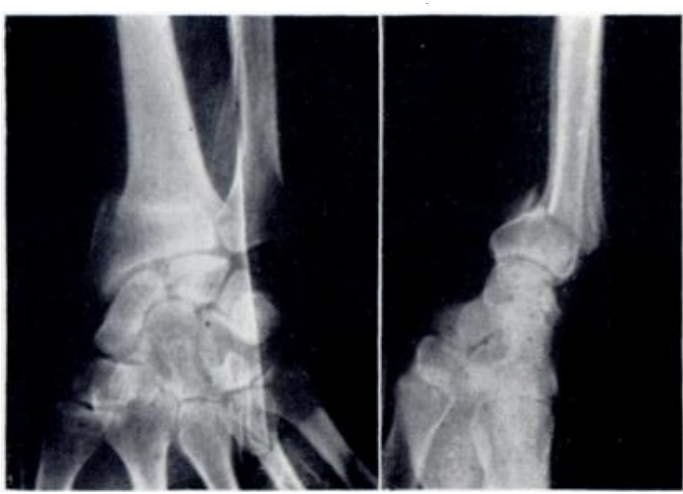

FIG. 3

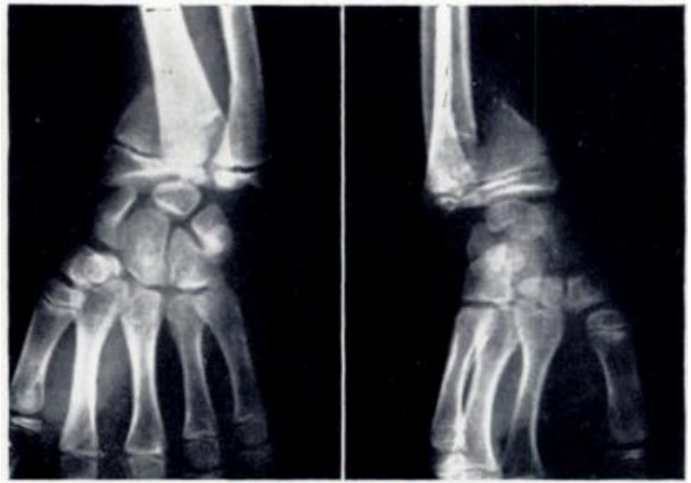

FIG. 4

Figure 3-A moderately displaced Type 3 fracture. Figure 4-A severely displaced fracture separation of the lower radial epiphysis in a girl aged 12.

\section{TREATMENT}

In forty-one cases treatment was by manipulation, sometimes repeated. There was nearly always much swelling of the hands and fingers, and after an initial period in a back-slab the wrist was later immobilised in plaster in varying positions, usually with ulnar deviation with or without dorsiflexion. Six patients had two manipulations and, despite variable improvements in the final position of the fragment, all had good functional results. Five of the six had the arm immobilised with an above-elbow plaster in full supination after the second manipulation. The plaster was retained for an average of six weeks and immobilisation was frequently followed by physiotherapy. Three patients were treated by internal fixation within the first week, using an Ellis plate.

\section{ASSESSMENT OF RESULTS}

Thirty-eight patients were examined personally, three months to six years after injury. Enquiry was directed to the mode of injury, the duration of disability, time off work. and in particular to residual pain and loss of function. On examination, note was made of deformity, power of grip and range of movement. Radiographs were taken. Six patients were not seen

VOL. 51 B, NO. 2, MAY 1969 
personally but answered a questionnaire. Their original and post-reduction radiographs were available and they are included in the assessment when possible. In order to assess results, points were given for functional ability and the amount of pain, the presence or absence of deformity, the amount of movement present and the radiological appearances. A total of thirteen points was possible. Results in the adult cases are shown in Table III. Three children all had good results.

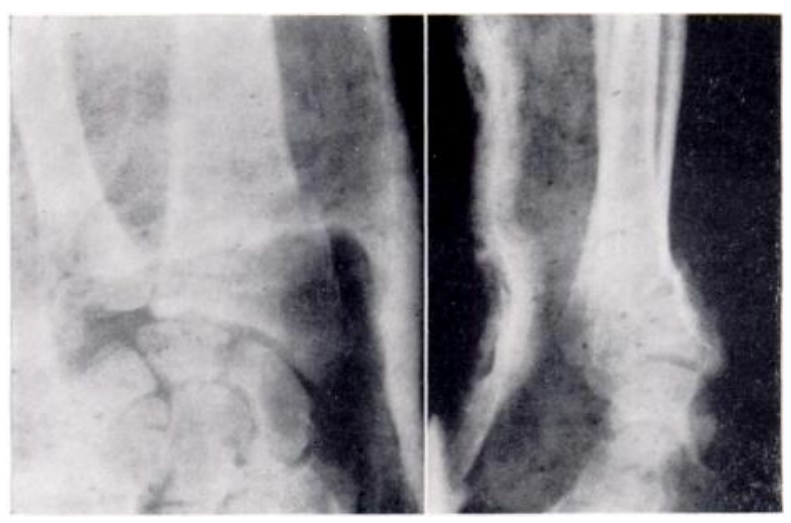

Fig. 5

An excellent reduction (Grade 0 ) of a Type 1 fracture.

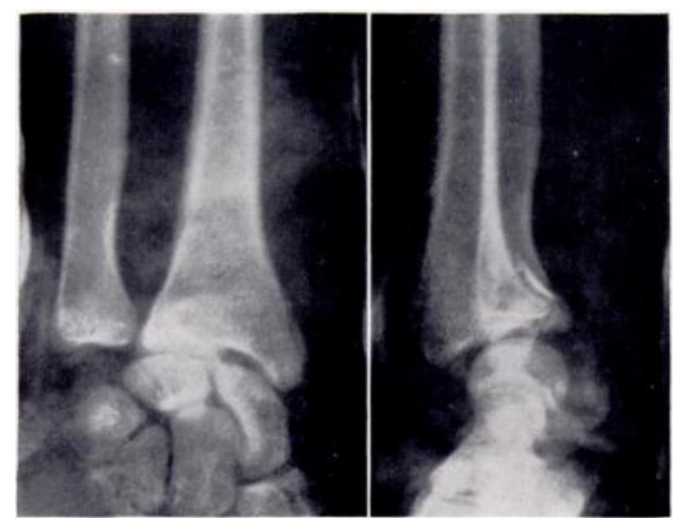

FIG. 6

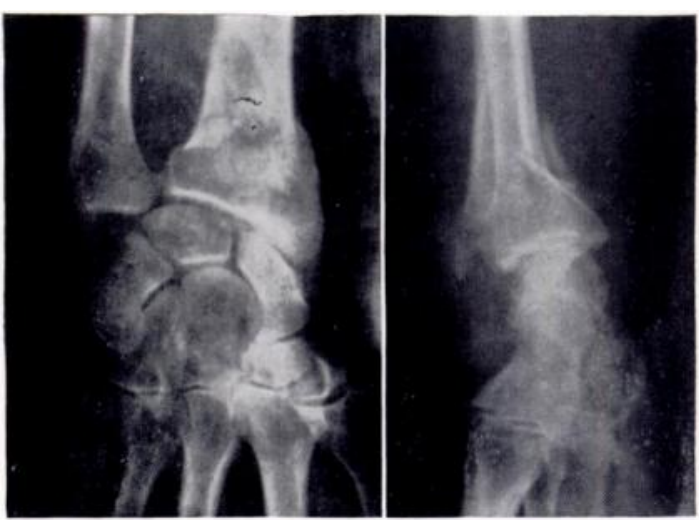

FIG. 7

Figure 6-A good reduction (Grade 1) of a Type 2 fracture which was not treated by supination in full arm plaster, but a good result was obtained in a man aged 18. Figure $7-\mathrm{A}$ poor reduction (Grade 2 ) of a Type 1 fracture; but with a good result without pain or disability in a woman aged 65 .

\section{RESULTS}

Table III shows that twenty-four out of thirty-five adults examined had good results: seven had fair result; and only four had poor results. The poor results all followed Type 2 fractures (anterior marginal with subluxation of carpus) with imperfect reduction (Tables IV and $\mathrm{V}$.

The Type 1 fracture was seen in nineteen out of thirty-eight patients examined and with one exception they were all over forty. Thirteen did well but only three of these showed perfect reduction of the fracture.

The Type 2 fracture was seen in thirteen patients, all examined: four were in men and nine in women. The age distribution was roughly the same as for the series as a whole, as was the overall standard of reduction, but these patients had more disability than the average, and the results were definitely not so good since they included all the poor results in the 
series (Table IV). Type 3 fractures, seen only in young and middle-aged patients, always did well. In adults, age in itself did not appear to influence the result.

Functional disability-This was complained of by twenty-one of the forty-four patients. The commonest complaint was of weakness in lifting, but weakness of rotation of the forearm and sometimes of dorsiflexion of the wrist were also noticed. Loss of function was commoner in Type 2 fractures than in the others.

TABLE III

Grading of Results in Thirty-five Adult Patients Examined Personally

\begin{tabular}{|l|l|l|}
\hline $\begin{array}{l}\text { Very little pain and loss of function, no evidence of osteo- } \\
\text { arthritis or joint surface irregularity in radiographs }\end{array}$ & Good & 24 \\
\hline $\begin{array}{l}\text { Some pain and/or loss of function: usually wrist deformity. } \\
\text { Very slight radiological changes at follow-up }\end{array}$ & Fair \\
\hline $\begin{array}{l}\text { Much pain and loss of function. Deformity of wrist. Osteo- } \\
\text { arthritis or much irregularity of joint surface in radiographs }\end{array}$ & Poor & 4 \\
\hline
\end{tabular}

TABLE IV

Distribution of Type of Fracture and Result in Thirty-eight Patients Sef.n at Follow-up

\begin{tabular}{|c|c|c|c|c|}
\hline & Type 1 & Type 2 & Type 3 & Children \\
\hline Good & 13 & 8 & 3 & 3 \\
\hline Fair & 6 & 1 & 0 & 0 \\
\hline Poor & 0 & 4 & 0 & 0 \\
\hline
\end{tabular}

TABLE V

Accuracy of Reduction Related to the Results in ThiRTy-eight Patients

\begin{tabular}{|c|c|c|c|c|c|}
\hline & $\begin{array}{l}\text { Grade of } \\
\text { reduction* }\end{array}$ & 0 & 1 & 2 & 3 \\
\hline \multirow{3}{*}{ Results } & Good & 9 & 13 & 5 & - \\
\hline & Fair & 0 & 6 & 1 & - \\
\hline & Poor & 0 & 3 & 1 & - \\
\hline
\end{tabular}

*Grade 0: excellent reduction. Grade 1: good reduction. Grade 2: fair or poor reduction. Grade 3: severe displacement.

Although Thomas stated that " with two exceptions all patients (nineteen) regained full pronation within three months" despite six weeks' full supination, this was far from the case with the present series of manipulated fractures. Most patients permanently lost a little rotation or flexion or both. The return of a practically full range of movement, as measured clinically in fifteen of the thirty-five adult patients examined, was associated with absence of disability in twelve and of pain in eleven of the fifteen. Of seven adult patients who had lost at least 30 degrees of movement in one or more directions, only one was free from pain and disability.

Clearly any method of treatment which favours an early return to full movement after an anatomical reduction of the fracture should give better results. Yet although the impression 
was gained that the three patients operated upon retained a good range of movement no evidence was found in those treated without operation that a good range of movement was dependent upon perfect reduction of the fracture.

The severity of the injury was judged by assessing the degree of displacement of the fragments and giving an arbitrary score from 0 to 3 for the pre-reduction and post-reduction radiographs (Table V). Severity as judged by this criterion had some influence on results, the slightly displaced fractures giving twelve good results in fourteen fractures, and the poor results all following moderately or severely displaced fractures. The standard of fracture reduction was also assessed (Figs. 5 to 7): not surprisingly it was found that there was a tendency for loss of function to be associated with indifferent reduction and that of the twenty-eight adults with good or perfect reduction twenty-two had good results.

Follow-up radiographs showed evidence of osteoarthritis in four cases, usually associated with some pain though never severe: the arthritis had usually developed since the injury in Type 2 fractures.

One patient's function had been improved and deformity corrected by excision of the lower end of the ulna some months after injury.

Length of follow-up-The impression was gained that the wrists continued to improve in function and freedom from pain for about a year to eighteen months, but the number of fair and poor results is insufficient to confirm this.

\section{DISCUSSION}

Mode of injury-Most patients were unable to remember the exact mechanism of the accident, but it is of interest that six patients were fairly certain that their fracture followed a fall upon the flexed wrist. Thomas noted that " none of the patients could recall falling upon the back

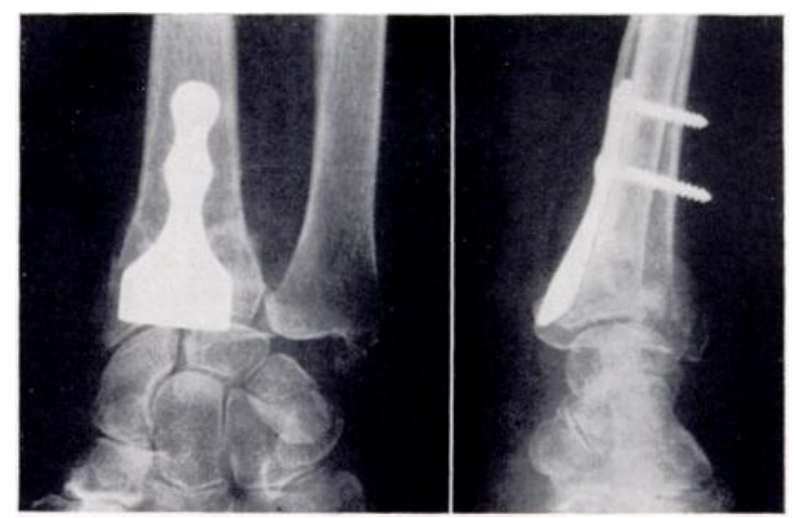

Fig. 8

An Ellis plate in position in a Type 1 fracture: clinically there was radial deviation. The range of movement was 60 degrees dorsiflexion and 35 degrees palmar flexion.

of their hands." Three other patients were positive that the injury was caused by violence from holding the handlebars of a crashed motor-cycle or scooter, but only one had the Type 3 fracture that Thomas associated with this kind of accident.

Method of treatment-Numbers were too small to confirm or disprove Thomas's advice to manage these patients by extreme supination. In five adult fractures so treated the standard of reduction was Grade 0 or Grade 1, and three of the results were good. It seems reasonable to treat all fractures with marked displacement by this method, as Thomas recommended, especially if they are of Type 2 with considerable damage to the articular surface of the radius, when palmar flexion of the wrist is also required to prevent recurrence of subluxation. 
Internal fixation was used in only three patients who could be traced, though other cases have been treated successfully by this method. The three former patients all had Type 1 fractures and fixation was by Ellis plate. The advantages should be that a good reduction is possible; plaster is not required afterwards and stiffness of the wrist is thereby discouraged. The plate (Fig. 8) does not, however, always prevent recurrence of radial displacement: of the three patients only one had a good result, the other two being fair.

Conclusions-Most Smith's fractures occur in middle age or later and are usually somewhat comminuted though not much displaced (Type 1). A good or fair result followed a good reduction regardless of the type of immobilisation. Some indeed did well in spite of imperfect reduction. Type 3 fractures (seen only in young and middle-aged patients) always did well. An above-elbow plaster in supination does not usually seem indicated for Type 1 and Type 3 fractures any more than for a straightforward Colles's fracture.

The prognosis is worse with an intra-articular fracture (Type 2), especially if markedly displaced. If well reduced such a fracture can give a good result, but because it is intra-articular and often occurs in old or middle-aged people it does not do well if poorly reduced. Fractures of this type were in fact responsible for three of the four patients who developed osteoarthritis of the wrist in later years, and the four poor results in this series were all Type 2 fractures.

A comparison of conservative and operative methods has not been possible in this series. A survey of the indications for operation is needed especially for bad Type 2 fractures. For these patients, if supination with some palmar flexion, as recommended by Thomas, and an above-elbow plaster do not prove sufficient to prevent displacement, then fixation with an Ellis plate might be indicated, but plaster may still be required to prevent recurrence of radial displacement. There seems to be no indication for internal fixation in Type 1 and Type 3 fractures, in which conservative methods are generally adequate. With the adoption of this policy it should be possible further to improve the overall results of treatment, which in this series were good in 70 per cent, fair in 19 per cent and poor in 11 per cent.

\section{SUMMARY}

1. Forty-four cases of Smith's type fractures are reviewed and emphasis laid upon the significance of the different fracture types.

2. Treatment is reviewed and recommendations made for future management.

I am grateful to $\mathrm{Mr} \mathrm{C}$. C. Jeffery for his kindly and helpful criticism during the preparation of this paper, and to the staff of the Records Departments of the Princess Elizabeth Orthopaedic and Torbay Hospitals for unstinted help in collecting material and typing the manuscript.

\section{REFERENCES}

Ellis, J. S. (1965): Smith's and Barton's Fractures. Journal of Bone and Joint Surgery, 47-B, 724.

Sмrт, R. W. (1847): A Treatise on Fractures in the Vicinity of Joints, and on Certain Forms of Accidental and Congenital Dislocations, pp. 129-175. Dublin: Hodges \& Smith.

TномаS, F. B. (1957): Reduction of Smith's Fracture. Journal of Bone and Joint Surgery, 39-B, 463.

VOL. 51 B, NO. 2,'MAY 1969 